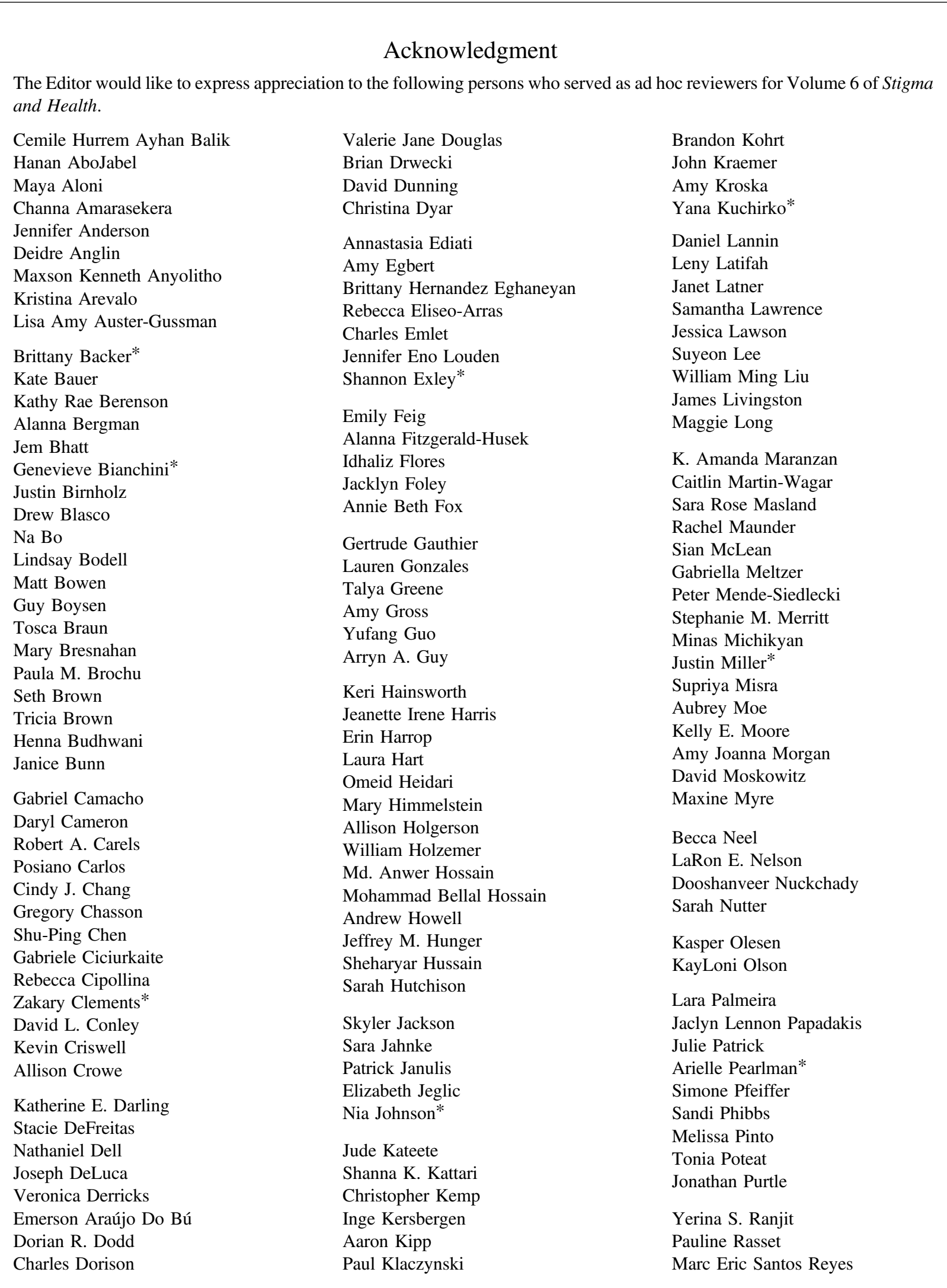


Patricia Roehling

Daniel Rosenfeld

Sharon Rostosky

Katie Rozzell*

\section{Rikki Sargent}

Krista Schroeder

Natasha Schvey

Whitney Scott

Sachin Shinde

Natalie Shook

Rannveig Sigurvinsdóttir

R. Sonia Singh

Rakesh Singh

Rachel A. Smith

Joshua M. Smyth

David Speed

Erin C. Standen

Anna Stone

Charles Stone
Jamie Studts

Lauren A. Stutts

Lois Takahashi

Rayner Kay Jin Tan

Ryan Thibodeau

Nhi-Ha Trinh

Wei-Mo Tu

Janet Turan

Paul Tuschman

Vasiliki Tzouvara

Emre Umucu

Allison Verhaak

Wilson Vincent

Hans-Werner Wahl

Allyn Walker

Anni Wang

Liang Wang
Xiaomei Wang

Petra Warschburger

Sara F. Waters

Lisa Webb

Marnie Wedlake

Brandon Weiss

Carolyn Weisz

Amy Werremeyer

Michelle L. West

Jenna Wilson*

Mathew Withers

Frank Yuan Wong

Benjamin Wood

Joyce P. Yang

Philip T. Yanos

Nelson C. Y. Yeung

Ben C. L. Yu

David Zelaya

Monica Zolezzi

* Denotes a coreviewer. 